\title{
Superhydrophobic Surfaces on 5052 Aluminum Alloy Obtained from LDH Film Modified with Stearic Acid for Enhanced Corrosion Protection
}

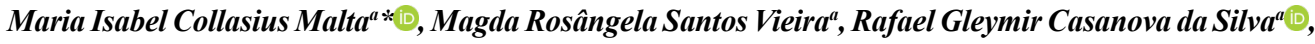 \\ Leonardo Mendonça Carneiro da Silva ${ }^{\circledR}$, Edval Gonçalves de Araújo ${ }^{a}$, Sara Horácio De Oliveira Maciel ${ }^{b}$ \\ Severino Leopoldino Urtiga Filho ${ }^{a}$ \\ ${ }^{a}$ Universidade Federal de Pernambuco, Departamento de Engenharia Mecânica, Av. Professor Moraes Rego, \\ 1235, Cidade Universitária, CEP 50670-901, Recife, PE, Brasil \\ ${ }^{b}$ Universidade Federal de Pernambuco, Departamento de Engenharia Química, Av. Professor Moraes Rego, \\ 1235, Cidade Universitária, CEP 50670-901, Recife, PE, Brasil
}

Received: December 9, 2018; Revised: August 26, 2019; Accepted: December 12, 2019

This paper aimed to develop and characterize superhydrophobic surfaces with anticorrosive properties obtained by the chemical modification of the 5052 aluminum alloy with variation of acid etching time, formation of lamellar double hydroxides (LDH) film and immersion in stearic acid. The specimens were etched in $\mathrm{HCl}(2 \mathrm{M})$ at 5, 10 and $30 \mathrm{~min}$. The aluminum plates were treated with aqueous solution of zinc nitrate $(0.1 \mathrm{M})$ in the presence of ammonia and then immersed in a stearic acid and ethanol solution $(1 \% \mathrm{w} / \mathrm{w})$ to reduce surface energy. Contact angles $(\mathrm{CA})$ were determined. Surface morphology and composition were analyzed by scanning electron microscopy (SEM) and X-ray energy dispersion spectroscopy (EDS), respectively. Linear polarization tests were performed to analyze corrosion resistance. The optimal superhydrophobic performance was obtained with a contact angle of $154^{\circ}$ for $30 \mathrm{~min}$ of acid etching. This condition also showed higher corrosion resistance, obtaining higher values of $\mathrm{E}_{\text {corr }}$ and lower values of corrosion current density.

Keywords: Superhydrophobic Surface, Micro/nanostructured Surface, LDH film, Aluminum alloy 5052, Corrosion.

\section{Introduction}

Biomimetic deals with the study of models, systems or processes that imitate nature, which has been adapted to solve the current problems of humanity ${ }^{1,2}$. The Lotus plant is considered a symbol of the sacred and one of the reasons is its ability to repel microorganisms and dust. This is due to an effect called the Lotus Effect, most commonly called superhydrophobicity, which occurs due to the existence of a surface roughness consisting of a microscopic structure and nanostructured substructure ${ }^{2,3}$.

This effect has attracted the interest of several sectors, resulting in the obtaining of several patents, because in addition to their self-cleaning property, these superhydrophobic (SHP) surfaces also have antifouling, anti-freezing and anticorrosive properties. Applying a hydrophobic material on the surface of a metal hinders the formation of electrochemical cells, since electrolyte contact with the surface will be limited. Thus, deterioration due to the corrosive process of metallic surfaces can be stopped or even completely prevented ${ }^{4,5}$.

Superhydrophobicity is achieved by combining the presence of a rugged micro and nanoscale-structure associated with low surface energy agents. It is characterized by a contact angle, between a droplet and a substrate, equal to or greater than $150^{\circ}$ and a sliding angle of less than $10^{\circ}$.

*e-mail: mariaisabelcollasiusmalta@gmail.com
Surfaces with water-repellent properties can generally be associated with two processes: (1) obtaining hierarchical micro/nanoscale binary structures, and (2) using chemical modification with low-energy materials ${ }^{7,8,9}$.

This hierarchical structure (micro/nanometric) can trap a large amount of air and minimize the real contact area between the surface and water, as explained by the CassieBaxter wetting model, which defines how liquid spreads when in contact with a solid surface. It assumes that air pockets are trapped below the drop, thus preventing the liquid from penetrating into the wells of the rough material ${ }^{5,10}$.

Among the techniques being used to obtain superhydrophobic surfaces are: anodizing processes, chemical modification, electroplating, laser treatment, counter etching by plasma, sol-gel processing, vapor deposition phase, colloidal assembly, deposition layer by layer, photolithography ${ }^{11,12}$. Regarding chemical modification procedures, in general, the literature has reported three procedural steps to obtain SHP surfaces: chemical etching ${ }^{13,14,15,16,17,18}$, obtain a precursor film of porous oxides or complex compounds ${ }^{19,20,21}$ and surface energy reduction ${ }^{14,16,22,23,24,25}$.

Layered double hydroxides (LDHs), or hydrotalcitelike compounds, are a class of synthetic anionic clays represented by the general formula: $\left[\mathrm{M}^{2+}{ }_{1-\mathrm{x}} \mathrm{M}^{3+}{ }_{\mathrm{x}}(\mathrm{OH})_{2}\right]$ ${ }^{\mathrm{x}} \cdot\left(\mathrm{A}^{\mathrm{n}-}\right)_{\mathrm{x} / \mathrm{n}} \cdot \mathrm{yH}_{2} \mathrm{O}$, where the cations $\mathrm{M}^{2+}$ and $\mathrm{M}^{3+}$ occupy the octahedral holes in a brucite-like layer and the anion $\mathrm{A}^{\mathrm{n}-}$ is located in the hydrated interlayer galleries. 
Recently, several studies have been carried out combining the properties of LDH films and surface reducing agents to obtain SHP surfaces in aluminum ${ }^{26,27,28,29}$.

Numerous studies point to the use of salt $\mathrm{Zn}\left(\mathrm{NO}_{3}\right)_{2} \cdot 6 \mathrm{H}_{2} \mathrm{O}$; and other salts such as $\mathrm{AlCl}_{3}$ and $\mathrm{Mg}\left(\mathrm{NO}_{3}\right)_{2} \cdot 6 \mathrm{H}_{2} \mathrm{O}$ in the presence of alkali compounds $\left(\mathrm{Mg}(\mathrm{OH})_{2}, \mathrm{NaOH}, \mathrm{NH}_{4} \mathrm{OH}, \mathrm{CH}_{4} \mathrm{~N}_{2}\right)$ to obtain precursor surfaces for subsequent treatment with surface energy reducing agents. One reason for its use is its high porosity, which increases its capacity to adsorb other molecules on its surface and because of its lamellar petal-shaped morphology, which allows obtain surfaces with micro/nano hierarchical structures that entrap a large amount of air ${ }^{30,31,32,33,34}$.

In solutions containing halide ions, these materials are susceptible to localized corrosion, limiting their use in marine environments. For this reason, alloys with better corrosion resistance are commonly used in marina applications such as $5 \mathrm{xxx}$ and $6 \mathrm{xxx}$ series aluminum alloys, although they are more resistant, these alloys also can present rupture in passive layer $^{12,13}$.

Besides the many existing anticorrosive methods, the development of superhydrophobic surfaces of aluminum has shown to be a good alternative for increasing the corrosion resistance of these materials. Anticorrosion protection is obtained by inhibiting the formation of electrochemical cells due to the reduced contact area between drop and substrate, thereby limiting the contact of the electrolyte with the surface ${ }^{35,36,37}$. Thus, it is possible to see the relevance of the study of superhydrophobic surfaces on aluminum substrates given their effectiveness in acting as anticorrosion protection, by delaying localized corrosion through water repellency.

This paper aimed to develop and to characterize anticorrosive superhydrophobic coatings on 5052 aluminum alloy obtained from chemical modified using acid etching in different times $(10,20$ and $30 \mathrm{~min})$, treatment with zinc nitrate for LDH films formation and acid stearic as reducing surface agent.

\section{Experimental}

\subsection{Materials}

From an aluminum alloy 5052 plate, the composition of which includes $\mathrm{Si}(0.5 \%)$; Fe (0.23\%); $\mathrm{Cu}(0.002 \%)$; Mn (0.058\%); $\mathrm{Mg}(2.324 \%)$; $\mathrm{Cr}(0.176 \%), \mathrm{Zn}(0.003 \%)$; $\mathrm{Ti}(0.013 \%)$ and the remaining element $\mathrm{Al}$. The solutions used were: aqueous acid solution of $\mathrm{HCl}(2 \mathrm{M})$, aqueous solution of hexahydrate zinc nitrate $(0.1 \mathrm{~mol} / \mathrm{L})$ in the presence of ammonium hydroxide and an ethanol and stearic acid solution $(28 \mathrm{mmol} / \mathrm{L})$; and sodium chloride solution $(35 \mathrm{~g} / \mathrm{L})$.

\subsection{Fabrication of the superhydrophobic aluminium alloy surface}

The Aluminum alloy 5052 plates $(20 \mathrm{~mm} \times 20 \mathrm{~mm} \times 3 \mathrm{~mm})$ were first polished with \#320, \#600 and \#1200 metallographic abrasive paper successively, cleaned with acetone and deionized (DI) water in an ultrasonic bath for $5 \mathrm{~min}$, and then dried with hot air. Secondly, the samples were etched with acid solution $\mathrm{HCl}$ (2M) for 10, 20 and 30 minutes, respectively. After the etching processing, the plates were immediately ultrasonically rinsed with DI water. The LDH film was obtained with a solution of $\mathrm{Zn}\left(\mathrm{NO}_{3}\right)_{2} \cdot 6 \mathrm{H}_{2} \mathrm{O}(0.1 \mathrm{~mol} / \mathrm{L})$ dissolved in $100 \mathrm{ml}$ of DI water and $4 \mathrm{~mL}$ ammonia added subsequently. The cleaned $\mathrm{Al}$ sheets were immersed in the solution and heated at $70^{\circ} \mathrm{C}$ for $3 \mathrm{~h}$. The products were washed with deionized water and dried at room temperature. Finally, aluminum alloy samples were modified by immersing in ethanolic stearic acid solution (STA) $1 \%$ (mass fraction) for $1.5 \mathrm{~h}$, then left at $80^{\circ} \mathrm{C}$ in an oven for $2 \mathrm{~h}$.

\subsection{Sample Characterization}

\subsubsection{Contact angle measurements}

The water contact angle was measured with $8 \mu \mathrm{L}$ deionized water droplets at room temperature $\left(25^{\circ} \mathrm{C}\right)$ using a horizontal microscope with an Optical Tensiometer (Biolin Scientific Theta Attension - OneAttension 3.0 Software). At least five parallel measurements were made for each sample, and the value of the average contact angles is reported.

\subsubsection{Morphology and composition characterizations}

The morphology of the aluminum compounds on the alloy surface was observed using a field emission type of Scanning Electron Microscope (SEM; Hitachi TM 3000). Morphologies of alloy surfaces after acid etching, modifying with zinc nitrate and SHP coating, and after treating with stearic acid were obtained. The chemical composition of the surface, before and after chemical modification with zinc nitrate in alkaline medium, was characterized by Energy Dispersive Spectroscopy (EDS) for which a Hitachi TM 3000 X-ray energy dispersive spectrometer associated with SEM was used with Quantax 70 software.

\subsubsection{Electrochemical experiments}

The polarization curves of electrochemical experiments were obtained using a computer-controlled electrochemical workstation (AUTOLAB PGSTAT 302N - NOVA software) in $3.5 \mathrm{wt} \% \mathrm{NaCl}$ solution at room temperature. The experiment was performed in a three-electrode cell system with a saturated calomel electrode (SCE) as a reference electrode, a platinum electrode as the counter electrode, and a $1 \mathrm{~cm}^{2}$ sheet of untreated aluminum alloy/ superhydrophobic aluminum alloy as a working electrode. 
Polarization curves were recorded at a sweep rate of 1 $\mathrm{mV} \mathrm{s}^{-1}$ in the range of -1900 to $1300 \mathrm{mV}$ from the open circuit potential obtained after $1.5 \mathrm{~h}$ of immersion. Each electrochemical test was repeated three times to ensure a good reproducibility.

\section{Results and Discussion}

\subsection{Surface morphology as assessed over variations in etching time}

The etching time of the 5052 aluminum alloy surfaces was investigated in this study in order to identify the influence of surface texture on obtaining superhydrophobic surfaces. Figure 1 shows the SEM images of the sanded surfaces and at different etching times of 10,20 and $30 \mathrm{~min}$ in $\mathrm{HCl}$ (2M) solution.

Figure 1 (a) is the SEM image of the non-treated $\mathrm{Al}$ surface showing the marks generated on the surface due to the sanding process. The sanded surface is characterized by the presence of defects, which are unidirectional soft scratches. Figure 1 (b) shows the alloy surface after 10 min of acid etching. The presence of some scratching remains, as can be seen in the image. However, the formation of micro-scale excavations begins.

When the etching time is increased to 20 and $30 \mathrm{~min}$ (Figure 1 (c) and Figure $1(d)$ ), in addition to the surface
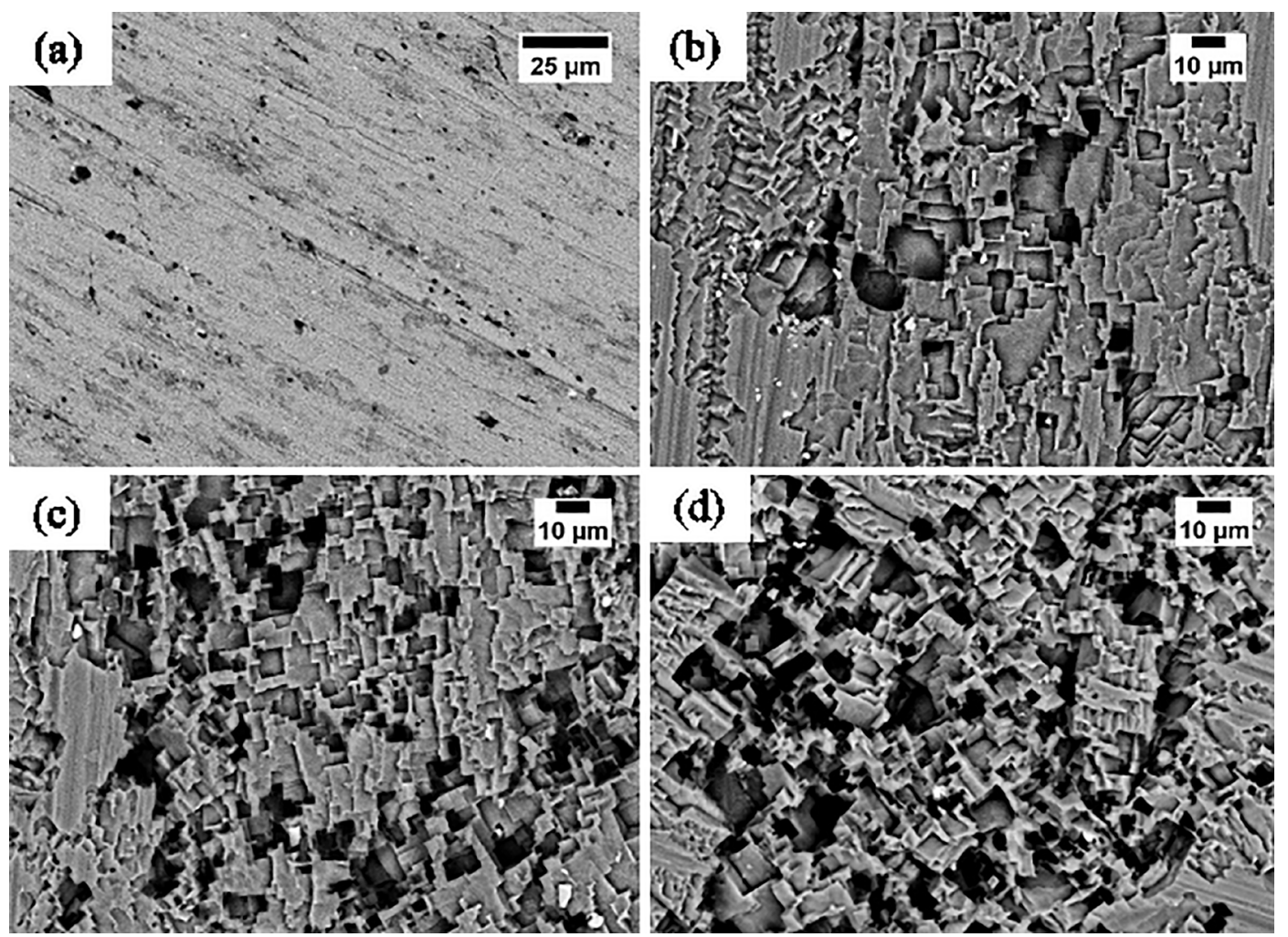

Figure 1. SEM of the surfaces of 5052 aluminum alloy: (a) after being sanded with \# 320, \#600 and \#1200 grit, sandpapers, successively; (b), (c) and (d) after etching in $\mathrm{HCl}(2 \mathrm{M})$ after 10, 20 and 30 min, respectively.

being more homogenous, excavations, with concaveconvex structures, on a micro- and nanoscale increase and these begin to interconnect along the surface. Similar results were obtained by Li et al $(2015)^{13}$, who showed that 5052 aluminum alloy samples in $\mathrm{HCl}(4 \mathrm{M})$ were etched at different times.

An excessive loss of thickness is not advantageous for engineering application materials; therefore, it is important to calculate the percentage loss of mass at all tested etching times. The result obtained was a mass loss of less than $2 \%$ for all etching times, as shown in the Figure 2.

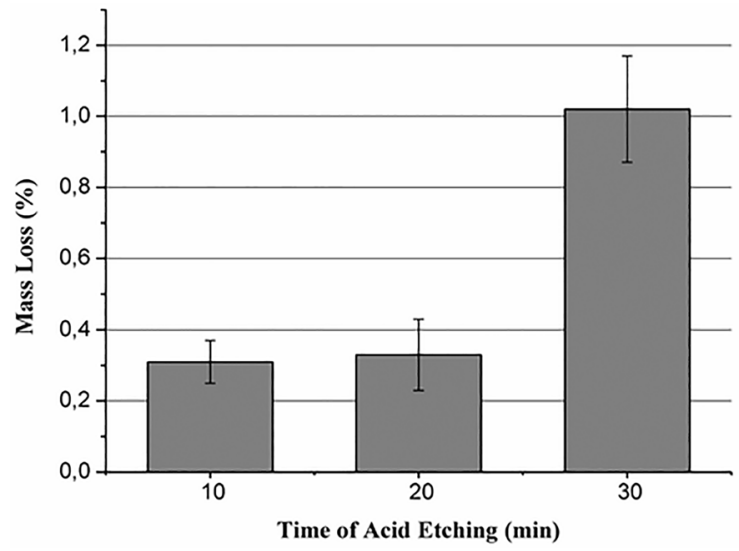

Figure 2. Mass loss of 5052 aluminum alloy in $\mathrm{HCl}(2 \mathrm{M})$ solution at different acid etching times 


\subsection{Composition and morphology of Super- hydrophobic coatings}

The surface morphology of a material is a crucial feature to achieve superhydrophobicity. The etching process guarantees the creation of a micrometer-scale roughness. The nanometric roughness was obtained by placing a solution of zinc nitrate in the presence of ammonium hydroxide.

Table 1 shows the results of EDS contents obtained in the sanded sample and after immersion in zinc nitrate, for the etched samples at the times of 10,20 and 30 min, identified as Z10, Z20 and Z30, respectively.

The aluminum and magnesium observed in the sanded surface, are characteristic elements of the 5052 aluminum alloy.
The presence of zinc, oxygen and nitrogen is observed after treatment with zinc nitrate, suggesting the deposition of zinc oxides and lamellar double compounds of the hydrotalcite type (LDH) on the surface of the worked alloy.

According to Guo, Wang and Wang ${ }^{38}$, the reaction of zinc nitrate in the presence of ammonium hydroxide can lead to the formation of zinc oxides and a lamellar double hydroxide $(\mathrm{LDH})$, structure of the hydrotalcite type of formula $\mathrm{Zn}_{(1-\mathrm{x})} \mathrm{Al}_{\mathrm{x}}(\mathrm{OH})_{2} \mathrm{NO}_{3(\mathrm{x})} \cdot \mathrm{H}_{2} \mathrm{O}$, which presents high porosity and due to the high surface area, can favor the retention of air and other hydrophobic substances being adsorbed.

SEM images of surfaces prepared at various acid etching times are shown in Figure 3: 10min (a); $20 \mathrm{~min}$ (b) and $30 \mathrm{~min}$ (c).

Table 1. EDS analysis on the surface after sanded process and after treatment with zinc nitrate in alkaline medium at different etching times of 10,20 and $30 \mathrm{~min}$, in $\mathrm{wt} \%$.

\begin{tabular}{lccccc}
\hline Samples & Al & Mg & O & N & Zn \\
\hline Sanded & 95.8 & 2.6 & 1.6 & - & - \\
Z10 & 2.9 & - & 18.4 & 0.1 & 59.8 \\
Z20 & 8.7 & - & 35.8 & 0.9 & 44.5 \\
Z30 & 8.0 & - & 35.4 & 1.3 & 41.6 \\
\hline
\end{tabular}


Figure 3. SEM images of aluminum alloy 5052 etched in $2 \mathrm{M} \mathrm{HCl}$ solution after treatment with zinc nitrate - (a) $10 \mathrm{~min}$; (b) $20 \mathrm{~min}$ and (c) $30 \mathrm{~min}$. 
Two distinct morphologies can be seen: the first consists of a flower-like structure and the other of a platelet or needle-like structure. As seen in the Zhang et al..$^{39}$, the treatment with zinc nitrate gave rise to a lamellar and petal-shaped structure that overlaps and unites, thus creating a micro-nanometric hierarchy which allows the creation of a superhydrophobic surface. As the etching time increases, a refinement of the structures formed occurs, which increases the diameter of the flower-like and petals-shaped structure with nanometric walls. The structures found in this study were very similar to those described by Guo, Wang and Wang ${ }^{38}$ who found microsphere morphologies that were similar to flowers ranging from 10 to $20 \mathrm{~mm}$ in diameter and nanometric substructures that were similar to petals with nanowalls that ranged from being 80 to $100 \mathrm{~nm}$ thick.

To achieve superhydrophobicity, surface energy reduction was accomplished by immersion of the zinc nitrate treated samples in stearic acid. The morphology of the aluminum surfaces after modification with the surface energy reducing agent is shown in Figure 4.

Stearic acid is a long chain carboxylic acid (octadecanoic acid - 18 carbons), the polar group (carboxyl group - $\mathrm{COOH}$ ) of which will interact with the surface treated with zinc nitrate and the carbonic chain, which has a hydrophobic character, is directed in the opposite way, thus leading to a reduction in surface energy and an increase in water repellency. The surface morphology after stearic acid treatment (Figure 4) is of a platelet-like structure, as obtained by Guo, Wang and Wang ${ }^{35}$. It is observed that when etching time is increased, the morphology becomes more refined and homogeneously distributed.

\subsection{Contact angle Analysis}

The images of the distilled water droplets are shown in Figure 5. Note that the contact angle increases as the time of etching increases. This treatment gave the samples a hydrophobic character, since they all presented water repellency, but superhydrophobicity, was only obtained in the sample etched for $30 \mathrm{~min}$, which presented a contact angle value greater than $150^{\circ}$ (Figure $5(\mathrm{~d})$ ). The surface that was only sanded presented a contact angle of $70^{\circ}$ which is classified as hydrophilic (Figure 5 (a)). The surface obtained after 10 $\min$ (Figure 5 (b)) and a 20 min of acid etching (Figure 5 (c)) showed hydrophobic behavior, with high water repellence and a contact angle less than $150^{\circ}$.

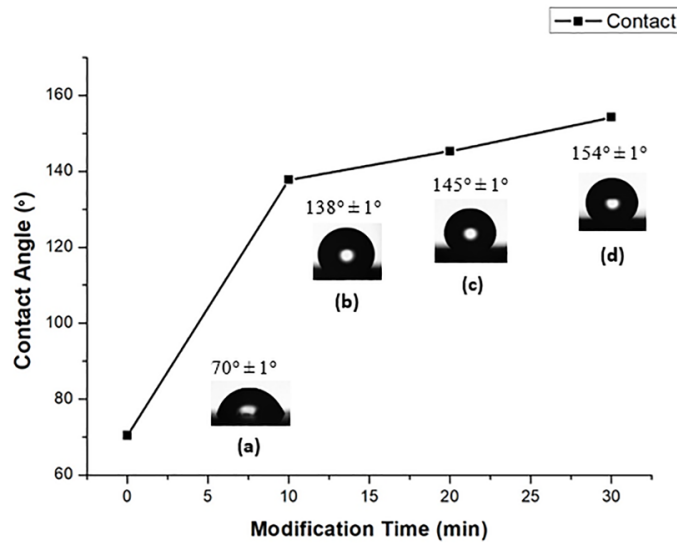

Figure 5. Images of the Drops: (a) sanded; treated with zinc nitrate and stearic acid after $\mathrm{HCl}(2 \mathrm{M})$ acid etching - (b) after $10 \mathrm{~min}$; (c) after $20 \mathrm{~min}$ and (d) after $30 \mathrm{~min}$ in $\mathrm{HCl}(2 \mathrm{M})$.

\subsection{Corrosion Resistance}

The corrosion resistance of the surfaces was evaluated by potentiodynamic polarization curves in $35 \mathrm{~g} / \mathrm{L} \mathrm{NaCl}$. Figure 6 shows the curves obtained for the sanded 5052 aluminum alloy sample and after treatment with stearic acid. The samples were identified as SA10, SA20, SA30 and SA0 to represent the $\mathrm{HCl}(2 \mathrm{M})$ etching times of 10,20 and 30 min and the sanded sample, respectively.

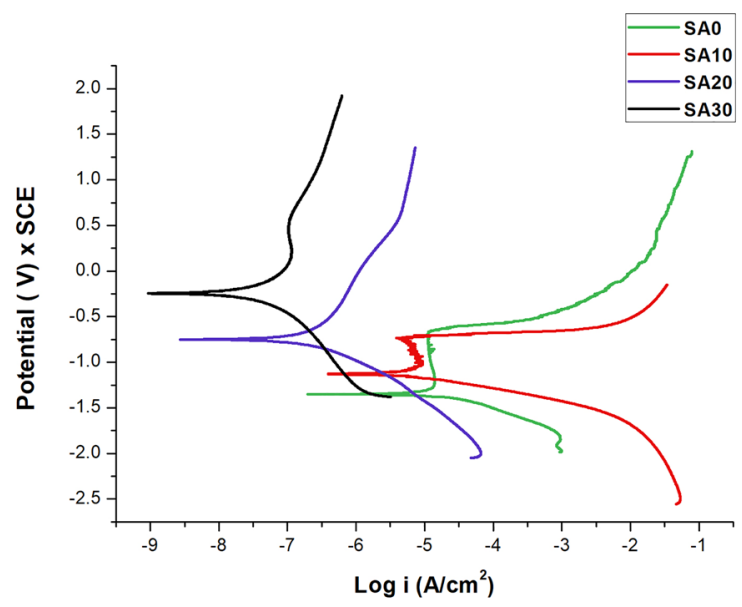

Figure 6. Potentiodynamic polarization curves for aluminum alloy 5052 after treatment in stearic acid and at different etching times in $\mathrm{HCl}(2 \mathrm{M})$.
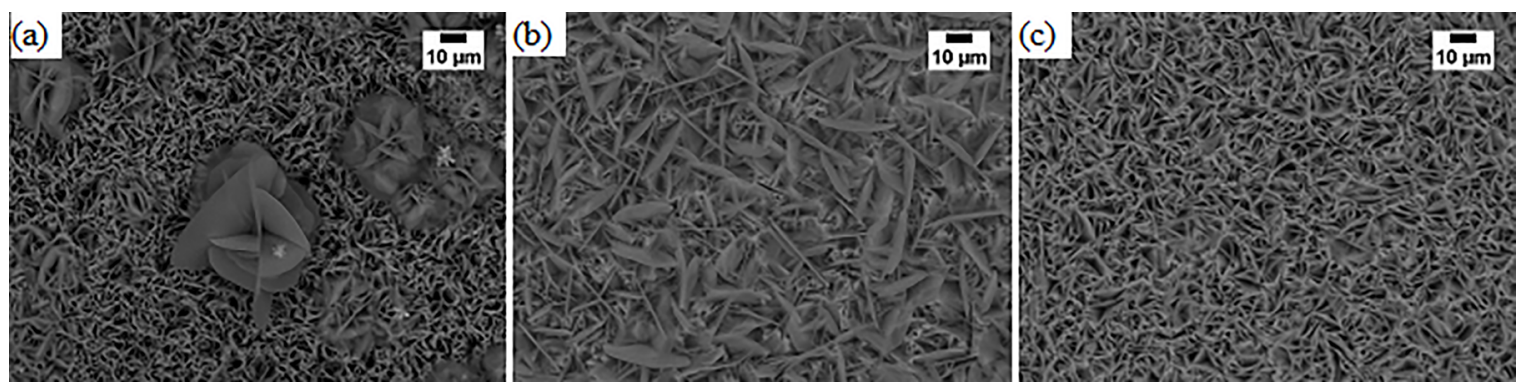

Figure 4. SEM images of aluminum alloy 5052 treated with stearic acid after $\mathrm{HCl}$ (2M) etching at different times: (a) $10 \mathrm{~min}$; (b) $20 \mathrm{~min}$ and (c) $30 \mathrm{~min}$. 
The red and blue curves (Figure 6) show, in the anodic zone of the graph, the typical behavior of a passive material such as aluminum alloy, where initially a reduction in anodic current density is obtained, followed later by an increase in current density, which characterizes the phenomenon of transpassivation, and is associated with the formation of localized pitting corrosion. All chemically modified surfaces showed an increase in corrosion potential values and a decrease in corrosion current density values relative to the sanded surface, indicating that the coatings were effective in anti-corrosion protection.

As Forooshani, Aliofkhazraei and Rouhaghdam ${ }^{5}$ explain, the increased protective character of surfaces occurs due to water repellency, which prevents the electrolyte from reacting with the anodic and cathodic areas of the material, thereby delaying the formation of electrochemical cells. Thus, the relationship between contact angle and corrosion protection can be confirmed.
The best results in terms of corrosion resistance were obtained for the 30 min etched sample, as can be seen from the corrosion potential, $\mathrm{E}_{\text {corr }}$, and the corrosion current density, $i_{\text {corr }}$,values shown in Table 2 .

The Table 2 shows the relationship between acid etching time and corrosion protection. Surfaces with longer $\mathrm{HCl}$ etching times have increased corrosion potential values, Ecorr, as well as decreased corrosion current, icorr, indicating a lower susceptibility of the surface to localized corrosion and proving the relevance of etching time in obtaining from SHP.

As can be observed in Figure 7 (a), the sanded sample presented generalized localized corrosion, indicating rupture of the passive layer through the action of chlorides. Hydrophobic samples (Figure 7 (b) and 7 (c)), etched for 10 and 20 min times respectively, showed coating degradation in several areas of the aluminum surface. In contrast, the superhydrophobic sample presented in Figure 7 (d), etched for 30 minutes, showed a considerable decrease in the degradation of surface coating.

Table 2. Corrosion potential $\left(\mathrm{E}_{\text {corr }}\right)$ and corrosion current density $\left(\mathrm{i}_{\text {corr }}\right)$ values of the sanded sample and etched samples (10, 20 and 30 min) obtained by Tafel extrapolation.

\begin{tabular}{lcc}
\hline Samples & $\mathbf{E}_{\text {corr }}(\mathbf{V} / \mathbf{S C E})$ & $\mathbf{i}_{\text {corr }}\left(\boldsymbol{\mu} \mathbf{A} / \mathbf{c m}^{2}\right)$ \\
\hline SA30 & -0.24 & 1.45 \\
SA20 & -0.71 & 4.72 \\
SA10 & -1.13 & 6,17 \\
SA0 & -1.29 & 6.29 \\
\hline
\end{tabular}
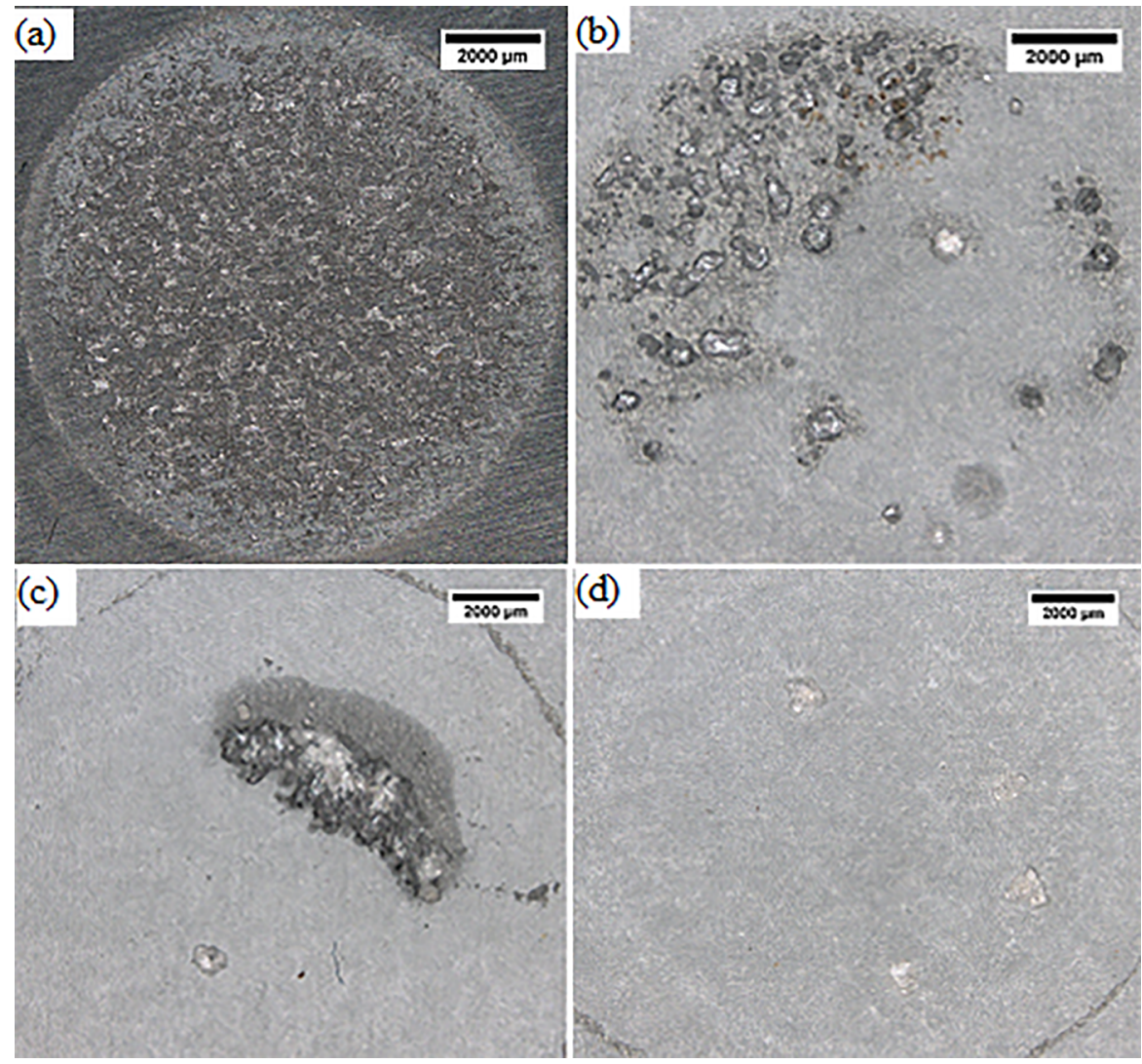

Figure 7. Images of aluminum alloy 5052 after electrochemical tests: (a) when sanded; treated with stearic acid after $\mathrm{HCl}(2 \mathrm{M})$ etching at different times: (b) 10min; (c) $20 \mathrm{~min}$ and (d) $30 \mathrm{~min}$. 
Through visual analysis of the samples, it is possible to observe a relationship between contact angle and anticorrosive protection.

The superhydrophobic samples presented minimal degradation of the coatings after electrochemical tests in chloride when compared to the surface of the uncoated aluminum alloy, which showed localized corrosion had occurred extensively.

\section{Conclusions}

Superhydrophobic surfaces on 5052 aluminum samples with excellent corrosion resistance were successfully prepared by a simple and low-cost method of chemical modification using an acid etching combined with LDH films and stearic acid. The results confirmed the influence of etching time on obtaining a homogeneous micro-nanometric structure on the surface.

The morphologies of the coatings after treatment with zinc nitrate, and consequently obtaining LDH films promoted the formation of porous surfaces, which, when associated with the surface energy reducing agent (stearic acid), enabled to obtain superhydrophobic surfaces.

The optimal superhydrophobic performance was obtained with a contact angle of $154 \pm 1^{\circ}$ for $30 \mathrm{~min}$ of acid etching. This condition also showed higher corrosion resistance, thus obtaining higher $\mathrm{E}_{\text {corr }}$ values and lower values of anodic current density.

The coatings developed in this study shows a technological application to protect metallic materials as aluminum and its alloys against corrosion, which are very susceptible to the action of chlorides and pitting formation.

\section{Acknowledgements}

The authors are grateful to FINEP, CNPq, CAPES, FACEPE and ANP/Petrobras for financial support.

\section{References}

1. Benyus JM. Biomimética: inovação inspirada pela natureza. São Paulo: Editora Cultrix; 2007.

2. Liang Y, Peng J, Li X, Huang J, Qiu R, Zhang Z, et al. Wettability and contact time on a biomimetic superhydrophobic surface. Materials. 2017;10(3):E254.

3. Barthlott W, Neinhuis C. Purity of the sacred lotus, or escape from contamination in biological surfaces. Planta. 1997;202:1-8.

4. Daoud WA. Self-cleaning materials and surfaces: a nanotechnology approach. New Jersey: John Wiley \& Sons; 2013.

5. Forooshani HM, Aliofkhazraei M, Rouhaghdam AS. Superhydrophobic aluminum surfaces by mechanical/chemical combined method and its corrosion behavior. Journal of the Taiwan Institute of Chemical Engineers. 2017;72:220-235.

6. Crick CR, Parkin IP. Preparation and characterization of superhydrophobic surfaces. Chemistry. 2010;16(2):3568-3588.
7. Roach P, Shirtcliffe NJ, Newton MI. Progess in superhydrophobic surface development. Soft Matter. 2008;4(2):224-240.

8. Liao R, Zuo Z, Guo C, Yuan Y, Zhuang A. Fabrication of superhydrophobic surface on aluminum by continuous chemical etching and its anti-icing property. Applied Surface Science. 2014;317:701-709.

9. Rezayi T, Entezari MH. Toward a durable superhydrophobic aluminum surface by etching and $\mathrm{ZnO}$ nanoparticle deposition. Journal of Colloid and Interface Science. 2016;463:37-45.

10. Oliveira LR. Modelagem bidimensional de hidrofobicidade e superhidrofobicidade em superficies de pilares [dissertation] Santa Maria (RS): Universidade Federal de Santa Maria - Centro de Ciências Naturais e Exatas; 2010.

11. Crawford RJ, Ivanova EP. Superhydrophobic surfaces. Melbourne: Elsevier; 2015.

12. Mohamed AMA, Abdullah AM, Younan NA. Corrosion behavior of superhydrophobic surfaces: a review. Arabian Journal of Chemistry: A. 2015;8(6):749-765.

13. Li XW, Zhang QX, Guo Z, Yu JG, Tang MK, Huang XJ. Lowcost and large-scale fabrication of a superhydrophobic 5052 aluminum alloy surface with enhanced corrosion resistance. RSC Advances. 2015;5(38):29639-29646.

14. Wu R, Chao G, Jiang H, Hu Y, Pan A. The superhydrophobic aluminum surface prepared by different methods. Materials Letters. 2015;142:176-179.

15. Ruan M, Li W, Wang B, Luo Q, Ma F, Yu Z. Optimal conditions for the preparation of superhydrophobic surfaces on al substrates using a simple etching approach. Applied Surface Science. 2012;258(18):7031-7035.

16. Huang Y, Sarkar DK, Chen XG. Superhydrophobic aluminum alloy surfaces prepared by chemical etching process and their corrosion resistance properties. Applied Surface Science. 2015;356:1012-1024.

17. Lv D, Ou J, Xue M, Wang F. Stability and corrosion resistance of superhydrophobic surface on oxidized aluminum in $\mathrm{NaCl}$ aqueous solution. Applied Surface Science. 2015;333:163-169.

18. Razavi SMR, Neisiany RE, Marjani A. A chemically durable superhydrophobic aluminum surface coated with silicon carbide nanoparticles and perfluoro acrylic copolymer. Theoretical and Applied Fracture Mechanics. 2018;94:181-185.

19. Zhang X, Zhang P, Wu Z, Zhang Z. Facile fabrication of stable superhydrophobic films on aluminum substrates. Journal of Materials Science. 2012;47(6):2757-2762.

20. Choi HJ, Shin JH, Choo S, Ryu SW, Kim YD, Lee H. Fabrication of superhydrophobic and oleophobic Al surfaces by chemical etching and surface fluorination. Thin Solid Films. 2015;585:76-80.

21. Cao Y, Zheng D, Li X, Lin J, Wang C, Dong S, et al. Enhanced corrosion resistance of superhydrophobic layered double hydroxide films with long-term stability on $\mathrm{Al}$ substrate. ACS Applied Materials and Interfaces. 2018;10(17):15150-15162.

22. Ou J, Shi Q, Chen Y, Wang F, Xue M, Li W. Superhydrophobic surfaces on diverse metals based on ultrafast sequential deposition of silver and stearic acid. Applied Surface Science. 2015;326:139-144. 
23. Feng L, Che Y, Liu Y, Qiang X, Wang Y. Fabrication of superhydrophobic aluminium alloy surface with excellent corrosion resistance by a facile and environment-friendly method. Applied Surface Science. 2013;283:367-374.

24. Wu R, Liang S, Pan A, Yuan Z, Tang Y, Tan X, et al. Fabrication of nano-structured super-hydrophobic film on aluminum by controllable immersing method. Applied Surface Science. 2012;258(16):5933-5937.

25. Wei Z, Jiang D, Chen J, Rem S, Li L. Fabrication of mechanically robust superhydrophobic aluminum surface by acid etching and stearic acid modification. Journal of Adhesion Science and Technology. 2017;31(21):2380-2397.

26. Meng Z, Xiaolu P, Liang W, Kewei G. Insitu grown superhydrophobic $\mathrm{Zn}$-Al layered double hydroxides films on magnesium alloy to improme corrosion properties. Applied Surface Science. 2015;337:172-177.

27. Hongyun C, Fazhi Z, Tao C, Sailong X, David GE, Xue D. Comparative analysis of the dynamic contact angles for two types of superhydrophobic layered double hydroxide film surfaces. Chemical Engineering Science. 2009;64(12):2957-2962.

28. Fen Z, Zhang CH, Song L, Zeng RC, Cui LY, Cui HZ. Corrosion resistance of superhydrophobic $\mathrm{Mg}$-Al layered double hydroxide coatings on aluminum alloys. Acta Metallurgica Sinica (English Letters). 2015;28(11):1373-1381.

29. Lu S, Chen Y, Xu W, Liu W. Controlled growth of superhydrophobic films by sol-gel method on aluminum substrate. Applied Surface Science. 2010;256(20):6072-6075.

30. Xiaoxiao G, Zang F, Evans DG, Duan X. Layered double hydroxide films: synthesis, properties and applications. Chemical Communications. 2010;46(29):5197-5210.
31. Guo Y, Wang Q, Wang T. Facile fabrication of superhydrophobic surface with micro/nanoscale binary structures on aluminum substrate. Applied Surface Science. 2011;257(13):5831-5836.

32. Zhang F, Sun M, Xu S, Zhao L, Zhang B. Fabrication of oriented layered double hydroxide films by spin coating and their use in corrosion protection. Chemical Engineering Journal. 2008;141(1-3):362-367.

33. Zhang F, Zhao L, Chen H, Xu S, Evans DG, Duan X. Corrosion resistance of superhydrophobic layered double hydroxide films on aluminum. Angewandte Chemie. 2008;47(13):2466-2469.

34. Zhang H, Yin L, Liu X, Weng R, Wang Y, Wu Z. Wetting behavior and drag reduction of superhydrophobic layered double hydroxides films on aluminum. Applied Surface Science. 2016;380:178-184.

35. Wang F, Guo Z. Insitu growth of durable superhydrophobic $\mathrm{Mg}-\mathrm{Al}$ layered double hydroxides nanoplatelets on aluminum alloys for corrosion resistance. Journal of Alloys and Compounds. 2018;767:382-391.

36. Zhang F, Liu ZG, Zeng RC, Li SQ, Cui HZ, Song L, et al. Corrosion resistance of $\mathrm{Mg}-\mathrm{Al}-\mathrm{LDH}$ coating on magnesium alloy AZ31. Surface and Coatings Technology. 2014;258:11521158 .

37. Wang B, Zhang L, Su Y, Xiao Y, Liu J. Corrosion behavior of 5A05 aluminum alloy in $\mathrm{NaCl}$ solution. Acta Metallurgica Sinica (English Letters). 2013;26(5):581-587.

38. Guo, Y, Wang Q, Wang, T. Facile fabrication of superhydrophobic surface with micro/nanoscale binary structures on aluminum substrate. Applied Surface Science. 2011;257(13):5831-5836.

39. Zhang Y, Wu J, Yu X, Wu H. Low-cost one-step fabrication of superhydrophobic surface on Al alloy. Applied Surface Science. 2011;257(18):7928-7931. 